\title{
Forecast of summer precipitation in the Yangtze River Valley based on South China Sea springtime sea surface salinity
}

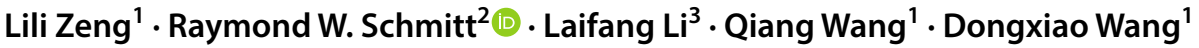

Received: 19 December 2018 / Accepted: 24 June 2019 / Published online: 4 July 2019

(c) The Author(s) 2019

\begin{abstract}
As a major moisture source, the South China Sea (SCS) has a significant impact on the summer precipitation over China. The ocean-to-land moisture transport generates sea surface salinity (SSS) anomalies that can be used to predict summer precipitation on land. This study illustrates a high correlation between springtime SSS in the central SCS and summer precipitation over the middle and lower Yangtze River Valley (the YRV region). The linkage between spring SSS in the central SCS and summer YRV precipitation is established by ocean-to-land moisture transport by atmospheric processes and land-atmosphere soil moisture feedback. In spring, oceanic moisture evaporated from the sea surface generates high SSS in the central SCS and directly feeds the precipitation over southern China and the YRV region. The resulting soil moisture anomalies last for about 3 months triggering land-atmosphere soil moisture feedback and modulating the tropospheric moisture content and circulation in the subsequent summer. Evaluation of the atmospheric moisture balance suggests both a dynamic contribution (stronger northward meridional winds) and a local thermodynamic contribution (higher tropospheric moisture content) enhance the summer moisture supply over the YRV, generating excessive summer precipitation. Thus, spring SSS in the SCS can be utilized as an indicator of subsequent summer precipitation over the YRV region, providing value for operational climate prediction and disaster early warning systems in China.
\end{abstract}

Keywords South China Sea $\cdot$ Yangtze River Valley $\cdot$ Sea surface salinity $\cdot$ Moisture flux $\cdot$ Summer precipitation

\section{Introduction}

Moisture evaporating from the ocean surface is regarded as the source and the largest element of the global water cycle (Schmitt 1995; Lagerloef et al. 2010; Schanze et al. 2010; Durack 2015). Moisture exchange between the ocean and atmosphere leaves an important imprint on the sea surface salinity (SSS) (Yu 2011). Globally, high (low) SSS is produced in regions of net freshwater loss (gain), where evaporation is greater (less) than precipitation, making it

Raymond W. Schmitt

rschmitt@whoi.edu

1 State Key Laboratory of Tropical Oceanography (LTO), South China Sea Institute of Oceanology, Chinese Academy of Sciences, Guangzhou 510301, China

2 Physical Oceanography Department, Woods Hole Oceanographic Institution, Woods Hole, MA 02543, USA

3 Earth and Ocean Sciences, Nicholas School of the Environment, Duke University, Durham, NC 27708, USA a natural rain gauge for measuring variations in the water cycle (Schmitt 2008; Durack et al. 2012; Terray et al. 2012). As the major moisture and latent heat sources for the rest of the climate system, high SSS regions are considered to be a valuable indicator for understanding the source regions of the global water cycle (Li et al. 2016a).

Previous studies mainly investigated the variation of salinity and treated it as a passive gauge of local freshwater forcing and other processes (Durack and Wijffels 2010; Skliris et al. 2014). In view of the salinity signal left by the net export of water vapor from the ocean that feeds precipitation on land, the feasibility of using salinity to predict terrestrial precipitation has become a research topic. Recent studies have found that seasonal anomalies in SSS in particular areas of the ocean have remarkable skill for predicting terrestrial rain in the next season in certain regions on land. Li et al. (2016a) provided evidence that spring SSS in the eastern subtropical North Atlantic is a useful predictor of rainfall in the Sahel of Afica in the subsequent monsoon season. In a further study, they showed that the spring SSS in the northwestern portion of the subtropical North Atlantic 
is significantly correlated with the summer precipitation over the U.S. Midwest (Li et al. 2016b). In recent decades, the relationship between the subtropical North Atlantic water cycle and US summer precipitation pattern has become closer, allowing SSS to be used to predict extreme rainfall events (Li et al. 2018). Liu et al. (2018) searched globally for teleconnections between autumn-lead SSS and SST signals and winter precipitation over the southwestern United States and were able to explain $67 \%$ of the variations in winter precipitation. These new results on the use of ocean salinity for predicting seasonal rainfall, and the similar geography of China and the US in being west of their respective subtropical gyres, motivated us to examine the predictability of rainfall over China using SSS.

The Yangtze River Valley (hereafter YRV) has increasingly become a key agricultural area and a booming economic zone within China. Controlled by the monsoon circulation, the temporal variation of precipitation in the YRV has distinct seasonality (Liu et al. 2017). The rainy season in the YRV is mainly concentrated in summer (June-August) and accounts for half the annual rainfall (Wu et al. 2003; Zhang 2015). In the YRV region, summer precipitation is associated thermodynamically with local humidity (Lei et al. 2011) and dynamically with the East Asia Summer Monsoon (Ding and Chan 2005). The migration of the East Asia Summer Monsoon, in turn, is preceded by the monsoon circulation in the South China Sea (SCS) (Tao and Chen 1987; Wang et al. 2004; He and Zhu 2015; Zhu and Li 2017). Throughout history, severe flooding in this region has been closely associated with extreme precipitation events (Zhang and You 2014) with losses in agriculture and economic disruption measured in billions of dollars. Thus, there is a pressing need to understand the mechanisms governing precipitation in the YRV region and to improve its seasonal prediction.

As a major moisture source (Fig. 1), the SCS has a significant impact on the summer precipitation in the YRV region (Zhou and Yu 2005; Gimeno et al. 2010). However, little attention has been given to the teleconnection between the SCS water cycle and summer precipitation over the YRV region. In this study, we aim to explore the processes by which spring SSS in the SCS is indicative of YRV summer precipitation, with an eye toward operational seasonal forecasts and China's disaster early warning system. The remainder of this paper is organized as follows. The data and methodology are presented in Sect. 2. The relationship between spring SSS in the SCS and summer precipitation over China is shown in Sect. 3. Thermodynamic and dynamic processes leading to YRV precipitation are documented in Sect. 4. Section 5 discusses the possible linkage between the spring SSS in the SCS and YRV precipitation. Finally, a discussion and conclusions are given in Sect. 6.

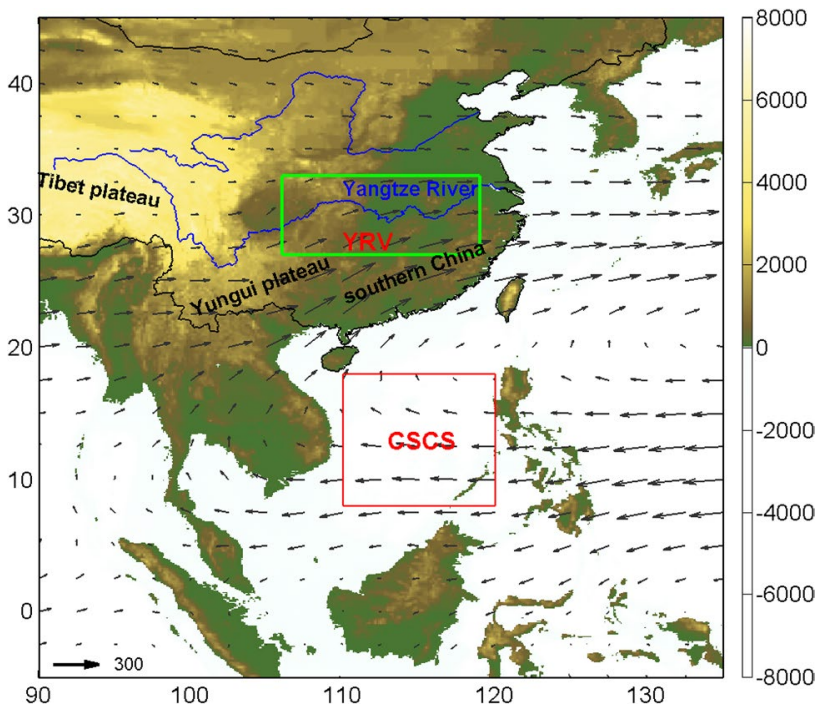

Fig. 1 Study area topography (color shading), climatology of spring moisture flux (gray vectors). The Yangtze and Yellow rivers are indicated by blue lines. The central South China Sea (SCS) and the middle and lower Yangtze River Valley (YRV region) are marked as red and green boxes, respectively

\section{Data and methods}

\subsection{Datasets}

We use the global unified gauge-based monthly precipitation from the National Oceanic and Atmospheric Administration's Climate Prediction Center (CPC; Chen et al. 2002). The CPC data at $0.5^{\circ} \times 0.5^{\circ}$ spatial resolution over the period 1950-2010 are chosen for this study and the linear trends are removed prior to the analyses.

The salinity data from the quality controlled Met Office Hadley Centre subsurface temperature and salinity objective analyses, EN4 (version 4.2.0; Good et al. 2013). While salinity data is sparse in the early years (Zeng et al. 2016a), the basin-averaged EN4 SSS in the SCS is in excellent agreement with recent Argo measurements (Figure is not shown). The monthly SSS is taken as the salinity data at $5 \mathrm{~m}$ depth. The EN4 SSS data at $1^{\circ} \times 1^{\circ}$ spatial resolution over the period 1950-2010 are chosen and the linear trend has been removed.

To assess the atmospheric processes linking spring SSS with summer YRV precipitation, horizontal wind vectors, and specific humidity from National Center for Environmental Prediction-National Center for Atmospheric Research (NCEP-NCAR) reanalysis data (Kalnay et al. 1996) at $2.5^{\circ} \times 2.5^{\circ}$ resolution over the period 1950-2010 are used to calculate moisture flux, moisture flux convergence, and the divergent component of moisture flux. We also analyzed CPC monthly soil moisture from the model-calculated 
product (Fan and van den Dool 2004) at $0.5^{\circ} \times 0.5^{\circ}$ spatial resolution over the period 1950-2010 to study the land surface water balance over Eastern China.

\subsection{Statistical analysis}

To extract the relationship between SSS and precipitation, a singular value decomposition (SVD) (Prohaska 1976; Bretherton et al. 1992; Wallace et al. 1992) was applied to the correlation matrix derived between the spring SSS in the SCS and summer precipitation over China. In this study, spring and summer are defined as the months March-May and June-August, respectively. In addition, the commonly used correlation, regression, and composite analyses are employed.

\subsection{Atmospheric and land-surface moisture balances}

To diagnose the processes that can build the linkage between the SSS in the SCS and YRV precipitation, both atmospheric and land-surface moisture balances are evaluated.

The moisture flux (MF) is calculated as,

$M F=\frac{1}{g} \int_{0}^{p_{s}} q \vec{V} d p$

where $g$ is the acceleration due to gravity, $q$ is specific humidity, and $\vec{V}$ is the horizontal wind vector. Because water vapor is concentrated below $300 \mathrm{hPa}$ (Zhou and $\mathrm{Yu} 2005$; $\mathrm{Li}$ et al. 2013; Seager and Henderson 2013), the moisture flux is integrated from the surface to the top level $(300 \mathrm{hPa})$ of the NCEP-NCAR reanalysis ( $\mathrm{Li}$ et al. 2016b).

The moisture flux convergence (MFC) is quantified as

$M F C=-\frac{1}{g} \nabla \cdot \int_{0}^{p_{s}} q \vec{V} d p$.

For a local atmospheric column, the moisture flux into and out of the column is balanced at a seasonal scale (Brubaker et al. 1993; Trenberth and Guillemot 1995; Li et al. 2016b), i.e., the difference between precipitation and evaporation is balanced by moisture flux convergence at time scales longer than 10 days (Brubaker et al. 1993):

$$
P-E=\underbrace{-\frac{1}{g} \nabla \cdot \int_{0}^{p_{s}} q \vec{V} d p}_{M F C}+\text { Residual }
$$

where $P$ is precipitation and $E$ is the land surface evaporation.

At the interface of the lithosphere and atmosphere, the soil moisture plays an important role in land-atmosphere interaction (Yang and Zhang 2016; McColl et al. 2017).
According to the water balance, the rate of change of soil moisture can be balanced by precipitation, evaporation, and some residual terms (Li et al. 2016a):

$$
\frac{\partial \mathrm{SM}}{\partial t}=P-E+\text { Residual }=\underbrace{-\frac{1}{g} \nabla \cdot \int_{0}^{p_{s}} q \vec{V} d p}+\text { Residual } .
$$

The effect of soil moisture in land-atmosphere coupling depends on the soil moisture memory. Atmospheric moisture and temperature anomalies can be triggered or modulated by a persistent soil moisture anomaly for several months (McColl et al. 2017). It is found that the spring surface thermal anomaly in the YRV region can last into summer and then affect the summer monsoon, due to the soil moisture memory of 2-3 months (Liu et al. 2017). The soil moisture memory is defined as the e-folding time of the soil moisture anomaly and is estimated from its one-month-lag autocorrelation coefficient (Jones 1975; Meng et al. 2013; Yang and Zhang 2016):

$\tau=-\mathrm{t} / \ln (\mathrm{r}(\mathrm{t}))$.

In Eq. (5), $r(t)$ is the autocorrelation function at lag time $t$, and $t$ is 1 month in this study. For example, soil moisture memory in May is calculated from the autocorrelation between soil moisture anomalies in May and June.

\subsection{Thermodynamic and dynamic contributions to atmospheric moisture balance}

The thermodynamic (specific humidity) and dynamic (wind vector) processes in the moisture flux equation can be decomposed into climatological and anomaly terms,. That is with, $q=q_{c}+q_{a}$, and $\vec{V}=\overrightarrow{V_{c}}+\overrightarrow{V_{a}}$, the moisture flux can be decomposed as:

$$
\begin{aligned}
\underbrace{\frac{1}{g} \int_{0}^{p_{s}} q \vec{V} d p}_{\text {Moisture flux }}= & \frac{1}{g} \int_{0}^{p_{s}} q_{c} \overrightarrow{V_{c}} d p+\underbrace{\frac{1}{g} \int_{0}^{p_{s}} q_{a} \overrightarrow{V_{c}} d p}_{\text {Thermodynamic }} \\
& +\underbrace{\frac{1}{g} \int_{0}^{p_{s}} q_{c} \overrightarrow{V_{a}} d p}_{\text {Dynamic }}+\frac{1}{g} \int_{0}^{p_{s}} q_{a} \overrightarrow{V_{a}} d p .
\end{aligned}
$$

The terms on the right-hand side of Eq. (6) correspond to the climatological moisture flux, the thermodynamic anomaly, the dynamic anomaly, and the covariance component.

The atmospheric moisture flux convergence can be decomposed into two terms, corresponding to mass convergence and moisture gradient, 


$$
\underbrace{-\frac{1}{g} \nabla \cdot \int_{0}^{p_{s}} q \vec{V} d p}_{M F C}=\underbrace{-\frac{1}{g} \int_{0}^{p_{s}} q \nabla \cdot \vec{V} d p}_{\text {Mass convergence }} \underbrace{-\frac{1}{g} \int_{0}^{p_{s}} \vec{V} \cdot \nabla q d p}_{\text {Moisture gradient }} .
$$

Similar to the decomposition of the moisture flux, by decomposing the specific humidity and wind vector into climatology and anomaly values, the mass convergence and moisture gradient terms can be further decomposed as:

$$
\begin{aligned}
\underbrace{-\frac{1}{g} \int_{0}^{p_{s}} q \nabla \cdot \vec{V} d p=}_{\text {Mass convergence }} & -\frac{1}{g} \int_{0}^{p_{s}} q_{c} \nabla \cdot \overrightarrow{V_{c}} d p \\
& \underbrace{-\frac{1}{g} \int_{0}^{p_{s}} q_{a} \nabla \cdot \overrightarrow{V_{c}} d p}_{\text {Thermodynamic }} \underbrace{-\frac{1}{g} \int_{0}^{p_{s}} q_{c} \nabla \cdot \overrightarrow{V_{a}} d p}_{\text {Dynamic }} \\
& -\frac{1}{g} \int_{0}^{p_{s}} q_{a} \nabla \cdot \overrightarrow{V_{a}} d p \\
\underbrace{-\frac{1}{g} \int_{0}^{p_{s}} \vec{V} \cdot \nabla q d p=}_{\text {Moisture gradient }} & -\frac{1}{g} \int_{0}^{p_{s}} \overrightarrow{V_{c}} \cdot \nabla q_{c} d p \\
& -\underbrace{-\frac{1}{g} \int_{0}^{p_{s}} \overrightarrow{V_{c}} \cdot \nabla q_{a} d p}_{\text {Thermodynamic }} \underbrace{-\underbrace{\frac{1}{g} \int_{0}^{p_{s}} \overrightarrow{V_{a}} \cdot \nabla q_{c} d p}_{g}}_{\text {Dynamic }} \\
& -\frac{1}{g} \int_{0}^{p_{s}} \overrightarrow{V_{a}} \cdot \nabla q_{a} d p .
\end{aligned}
$$

The terms on the right-hand side of Eqs. (7) and (8) correspond to the climatology of mass convergence and moisture gradient, the thermodynamic component, the dynamic component, and the covariance component, which is neglected in this study because it is at least one order of magnitude smaller than the others (Li et al. 2016b).

\section{Relationship between SCS SSS and YRV precipitation}

To examine the relationship between SSS in the SCS and precipitation over China, the SVD method is applied to the correlation matrix of spring SSS and summer precipitation. The first mode has a total explained covariance of $42.6 \%$ for the period 1950-2010. The positive SSS anomaly in spring covers the entire basin of the SCS (Fig. 2a). The most significant SSS signal appears on either side of the Luzon Strait and the Philippine Islands, and in regions west of the Luzon Strait and in the eastern central SCS. The positive SSS anomaly is weaker in the southern and western parts of the basin (Fig. 2a). Note that there is a low salinity core just east of the mouth of the Yangtze River, indicating the effect of river runoff or local precipitation which is evident in the SVD mode of precipitation. The positive anomalies of summer precipitation corresponding to the above normal SSS are mainly located in northern China, south of the middle Yellow River, and over the YRV region (Fig. 2b). Negative precipitation anomalies occur in relatively small regions such as southern China and the Tibetan Plateau. The SVD time series of spring SSS shows a particularly high correlation with summer precipitation in China, with a coefficient of 0.73 (Fig. 2c). In summary, the first SVD mode indicates a lead relationship between high spring SSS in the SCS and increased summer precipitation over the YRV. The spring SCS SSS signal leads precipitation by one season, suggesting that it can be used as a predictor of precipitation over China.

To investigate the significant signal explained by the first SVD mode, the percentage of variance of leading mode spring SSS and summer precipitation was calculated. We reconstructed the precipitation time series using the first SVD mode and then calculated the corresponding variance versus the original total variance at each grid cell (Fig. 3). The most significant spring SSS variance appears in the central SCS (Fig. 3a). The prominent summer precipitation variance corresponding to the higher spring SSS are mainly located over the YRV region, and relatively small regions such as southern China and the Tibetan Plateau and northwestern region. Both the spring salinity in the central SCS and summer precipitation in the YRV region share significant variance with the first SVD mode. This also implies that the spring SSS in central SCS has remarkable skill for predicting subsequent summer precipitation over YRV region.

Previous studies suggested that the interannual variability of western Pacific including the SCS is closely related to ENSO activity (Zhou et al. 2009; Li et al. 2017). To ensure the independence of the SSS of the central SCS from ENSO, the correlation between the SSS and ENSO can be examined. It is worth noting that there are insignificant correlation coefficients between the ENSO index (Niño 3.4) and the first mode springtime SSS and summer precipitation time series of 0.14 and 0.01 , respectively. In addition, to see if the spring SSS in the central SCS is a delayed response to boreal winter El Nino forcing, the correlations of the winter Niño 3.4 index with the SSS in the subsequent spring is examined. The correlation coefficient 0.34 shows they are not highly correlated. That is to say, this spring SSS pattern in the central SCS is largely independent of ENSO, and contributes significant predictive value for summer precipitation over the YRV region.

To further show the relationship between them, precipitation over China is regressed onto spring SSS in the central SCS (Fig. 4). The regressed precipitation shows a seasonal variation from spring to summer. In spring, the most significant precipitation signal associated with SSS exhibits a zonal dipole pattern that is negative in southwestern China and positive in southeastern China. In summer, the most 


\section{(a) Spring SSS}

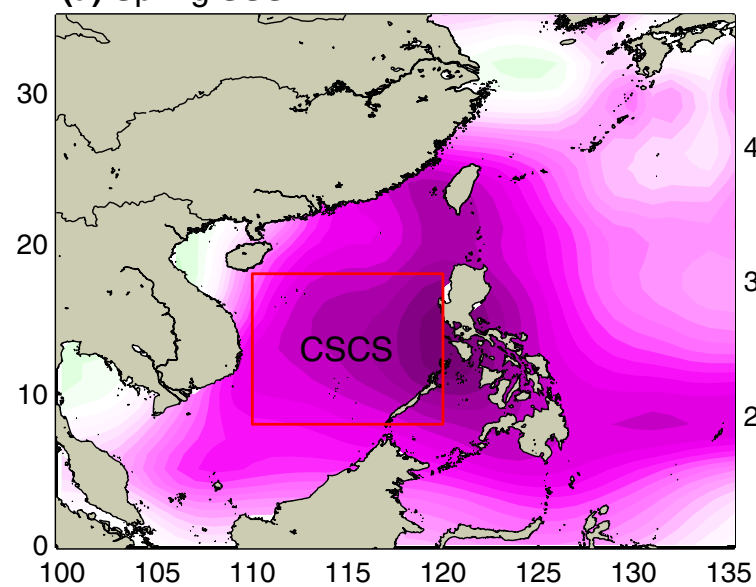

\section{The first SVD modes, $42.6 \%$}

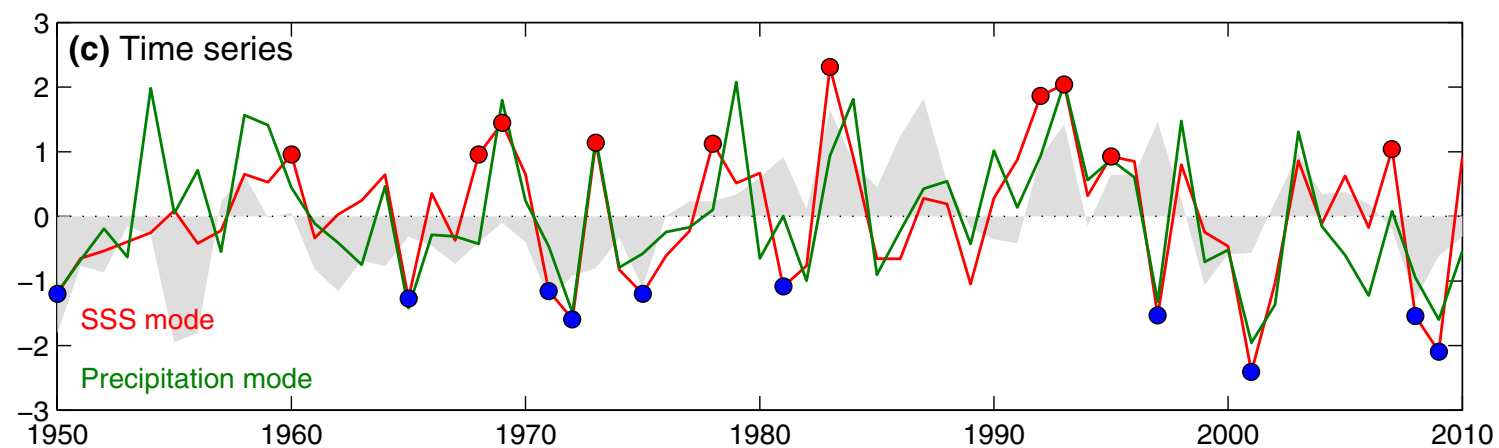

Fig. 2 The first SVD mode of a spring (March-May) SSS anomaly and b summer (June-September) precipitation over China. The central SCS and the YRV region are marked as red and green boxes, respectively. c Time series of Niño 3 index (shaded, gray) and the (b) Summer precipitation

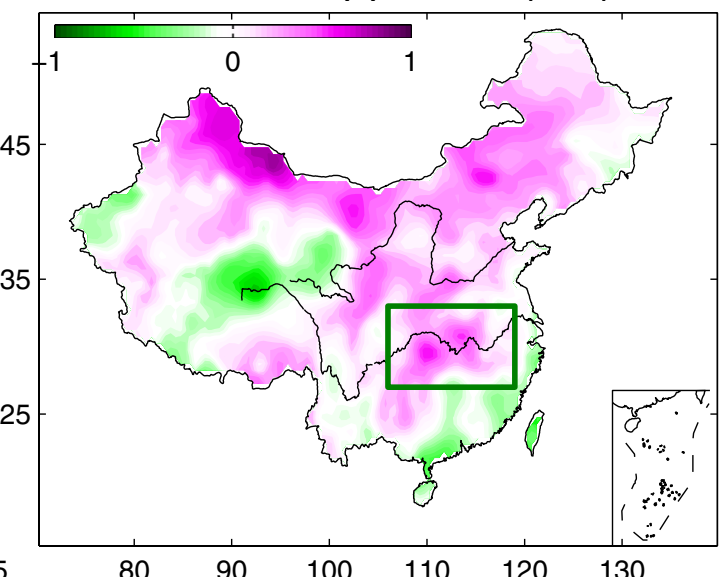

first SVD modes of SSS anomaly (solid red curve) and precipitation (solid green curve). The red and blue dots mark the highest (highSSS) and lowest (low-SSS) 10 years used for composite analysis in the study (a) Spring SSS

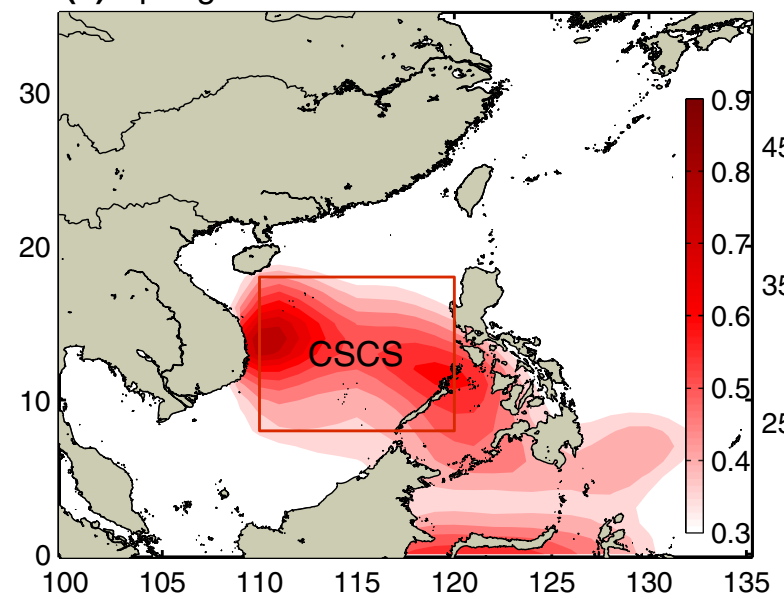

(b) Summer precipitation

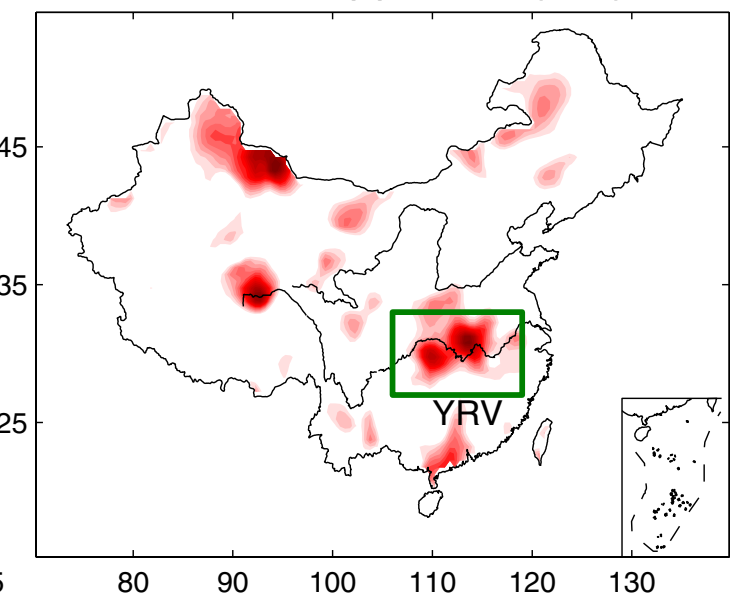

Fig. 3 The variance of the first SVD mode of a spring (March-May) SSS anomaly and b summer (June-September) precipitation over China. Values higher than 0.3 are shaded. The central South China
Sea (CSCS) and the middle and lower Yangtze River Valley (YRV region) are marked as red and green boxes, respectively 
(a) Regressed spring precipitation

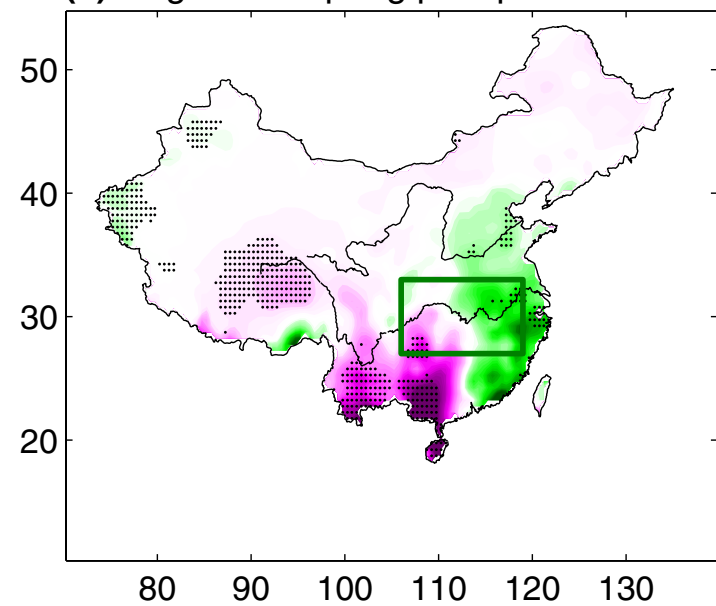

(b) Regressed summer precipitation

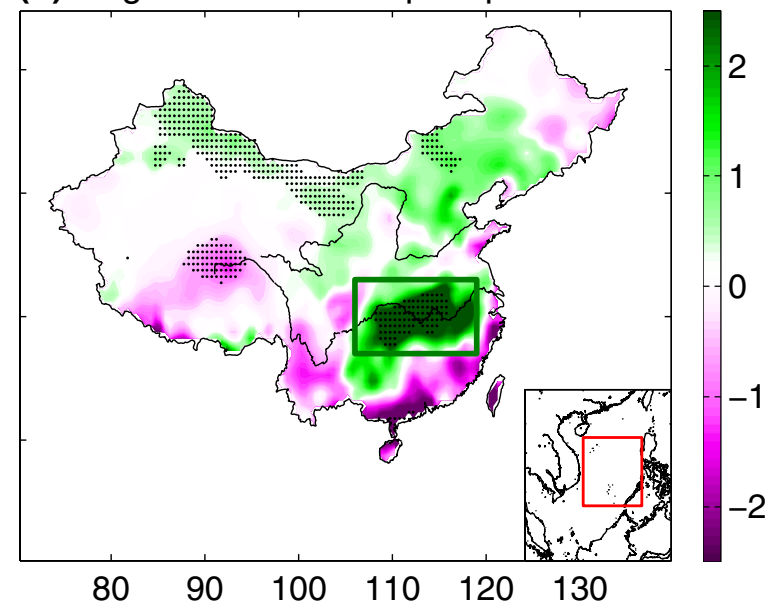

Fig. 4 China precipitation anomaly regressed upon spring SSS in the central SCS (subdomain is shown in the inset): a spring and b summer. Dotted areas indicate that correlation coefficients are significant at the $95 \%$ confidence level. The YRV region is marked as a green box

significant precipitation anomaly associated with SSS is found over the YRV region, with a positive anomaly exceeding $2 \mathrm{~mm} /$ day, more than $30 \%$ of the climatological mean (in the range $4-7 \mathrm{~mm} /$ day). Similar to the distribution of the correlation coefficient, the regressed summer precipitation also shows a meridional dipole pattern that is negative in southern China and positive in the YRV region. The magnitude of the precipitation anomaly in northern China associated with SSS is much smaller than that in southern China and the YRV region.

To understand the percentage of summer YRV precipitation accounted for by the spring SSS in the central SCS, the standard deviation of regressed summer precipitation on spring SSS index versus the standard deviation of original summer precipitation at each grid cell is calculated. Up to $50 \%$ of the variance of summer YRV precipitation is accounted for by the spring SSS in central SCS. In the following sections, we will focus on the mechanisms linking the springtime SSS anomaly in the central SCS and summer precipitation anomalies over the YRV.

\section{Thermodynamic and dynamic processes leading to YRV precipitation}

SSS variations have come to be recognized as an indicator of ocean-to-land moisture transport through the atmospheric moisture flux (Gimeno et al. 2010; Lagerloef et al. 2010; Trenberth et al. 2011; Schmitt 2008; Li et al. 2016a). To explore the connection between spring SSS in the central SCS and summer precipitation in the YRV, we examine the atmospheric moisture balance in the YRV region using the NCEP reanalysis data (Kalnay et al. 1996). From 1950 to

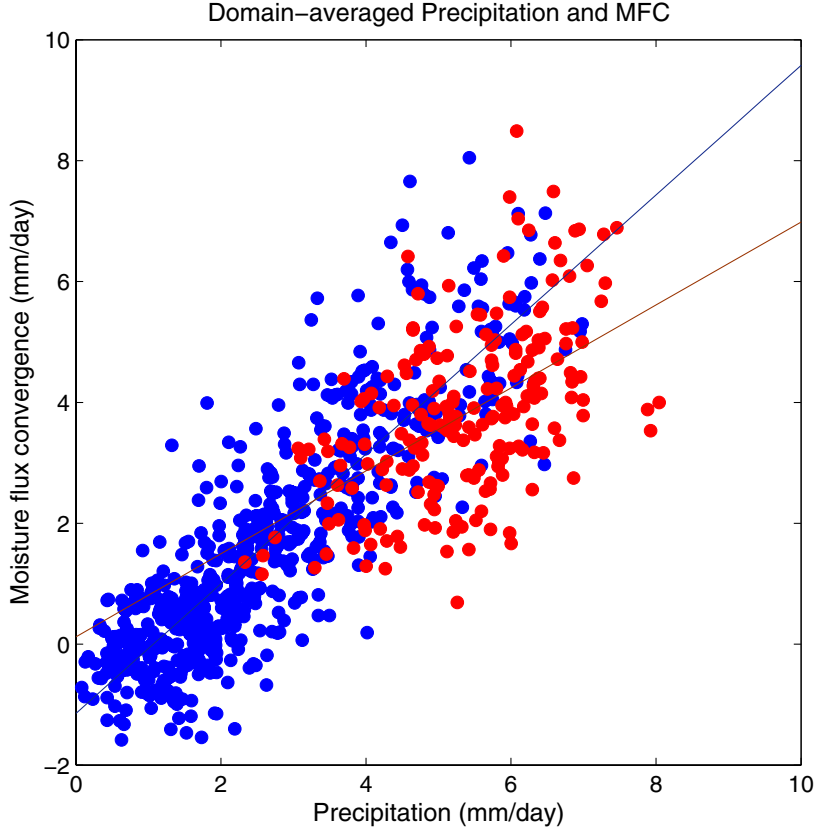

Fig. 5 Relationship between monthly mean domain-averaged precipitation and moisture flux convergence over the YRV region. Red dots are for summer and blue dots are for the other seasons. The red (blue) line is the least squares linear best-fit line to the summer season (other seasons) sample set

2010, summer precipitation in the YRV is highly correlated with the atmospheric moisture flux convergence (MFC), with a correlation coefficient of 0.84 between domain-average precipitation and MFC (Fig. 5).

Due to the close relationship between the precipitation and atmospheric MFC, the summertime MFC is composited to identify the causes of the excessive precipitation over the 
YRV following salty springs in the SCS (Fig. 6). The high and low SSS cases for the composite analysis are the years when the SSS anomalies are ranked as the top and bottom ten cases in the SVD time series (red and blue dots marked in Fig. 2c). In spring, the moisture flux divergence associated with high salinity events is located in the eastern central SCS, leading to anomalously large water export (Fig. 6a). To identify the areas where the moisture flux will converge, the divergent component of moisture flux is derived by solving the Poisson equation (Lynch 1988; Chen and Pfaendtner 1993; Li et al. 2016a, b). The divergent component of moisture flux indicates that most moisture flux from the central SCS converges directly on southeastern China, the lower Yangtze River and the East China Sea, while a small branch is transported to the Tibetan Plateau. As a result, more moisture converges over southeastern China, the lower reach of the Yangtze River, and the East China Sea. The spring converged moisture guarantees more precipitation over eastern China, coinciding with the precipitation anomaly regressed upon spring SSS (Fig. 4a). In summer, the moisture flux divergence anomaly associated with high salinity years moves northward to the northern SCS and southern China (Fig. 6b). The northward shift of moisture anomaly export region converges moisture over the YRV, resulting in continuously increased moisture flux convergence and excessive precipitation there.

The anomalous MFC can be caused by either atmospheric dynamics or thermodynamics, which can be evaluated based on Eq. 6. The dynamic processes (the product of wind anomalies and climatological humidity) and thermodynamic processes (the product of climatological winds and humidity anomalies) that lead to enhanced moisture flux and convergence are shown in Fig. 7. According to our analysis, dynamic processes and thermodynamic processes combined contributed to the anomalous MFC (Fig. 7). The effects of dynamic processes and thermodynamic processes are the main contributors to the anomalous MFC in the western and eastern YRV region, respectively.

The importance of the thermodynamic and dynamic contributions is further decomposed into mass convergence and moisture gradient terms (based on Eqs. 7-9). The dynamic and thermodynamic mass convergence processes weaken MFC in the region (Fig. 8a, b). In contrast, the dynamic and thermodynamic moisture gradient terms play dominant roles in the increased moisture flux convergence (Fig. 8c, d). The moisture gradient contribution is manifest as an enhanced dynamic term in the western YRV region and an enhanced thermodynamic term in the eastern YRV region. (a) Spring MFC \& divergent MF

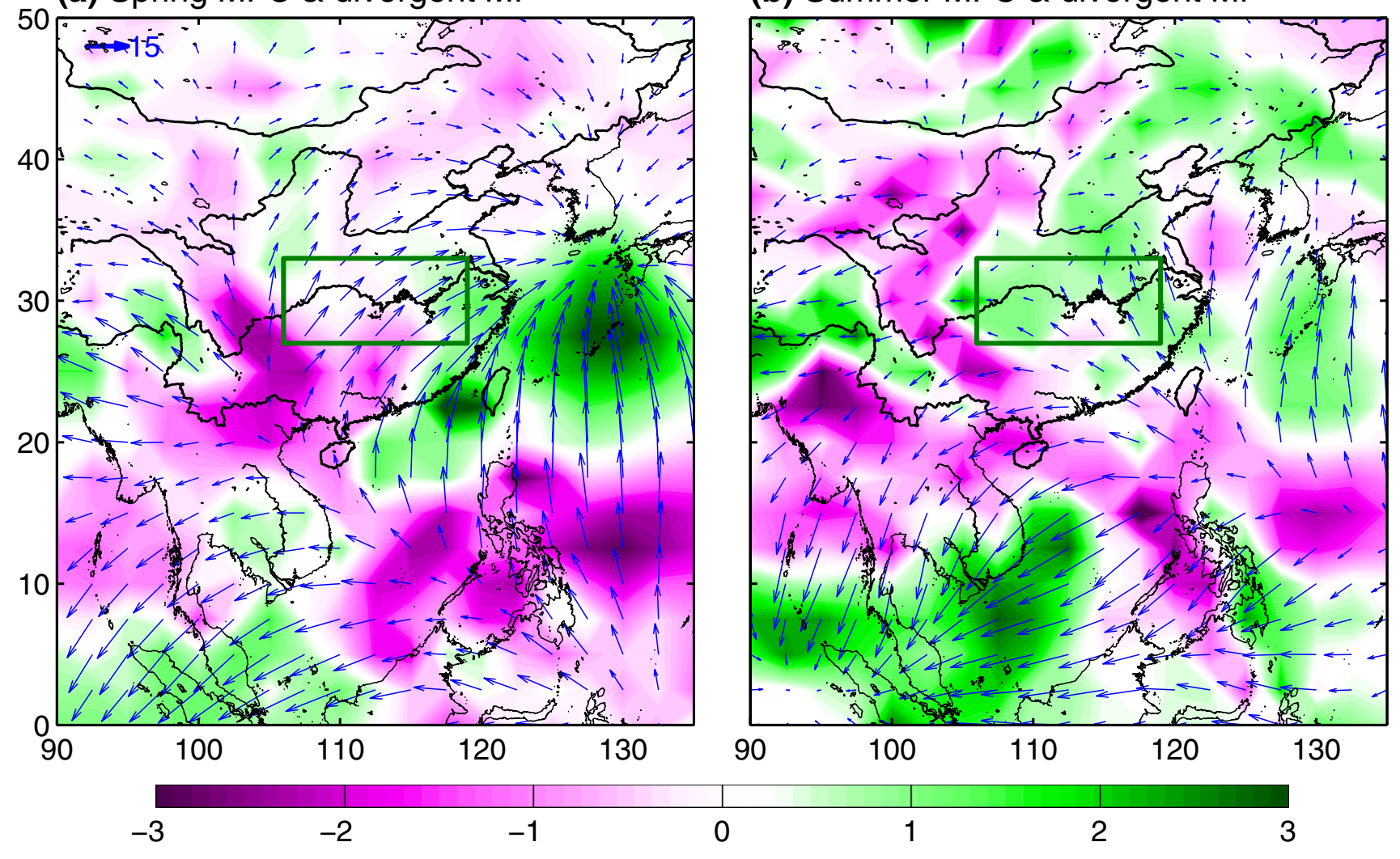

Fig. 6 Moisture flux convergence anomaly (shaded; $\mathrm{mm} /$ day) and the divergent component of moisture flux (vectors; $\mathrm{kg} \mathrm{m}^{-1} \mathrm{~s}^{-1}$ ) composited as the difference between the highest and lowest ten salinity years shown in Fig. 2c: a spring composite; b summer composite 
(a) Dynamic contribution by $\mathrm{V}_{\mathrm{a}} \& \mathrm{Q}_{\mathrm{c}}$

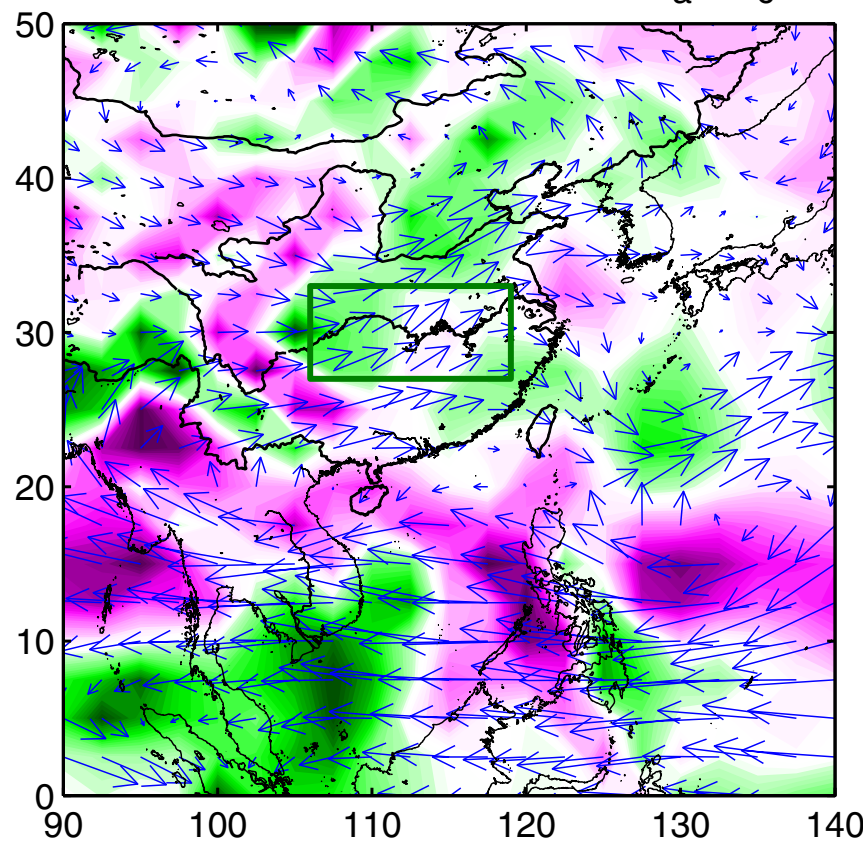

(b) Thermodynamic contribution by $V_{c} \& Q_{a}$

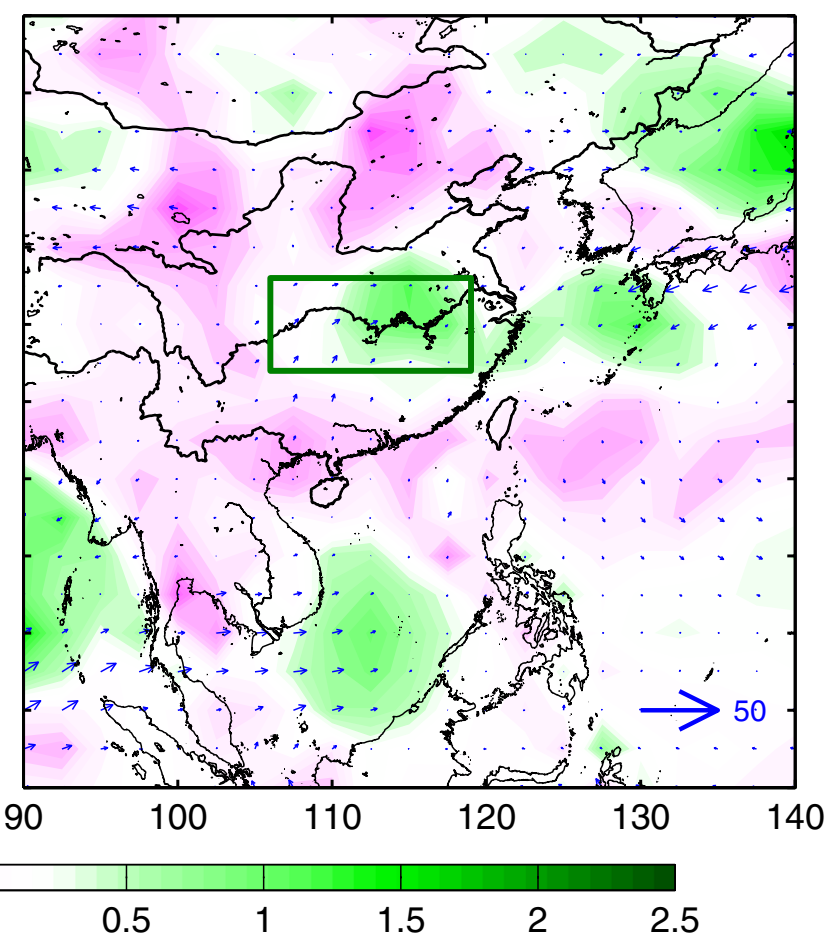

Fig. 7 a Dynamic and b thermodynamic contributions to summer moisture flux (vectors; $\mathrm{kg} \mathrm{m}^{-1} \mathrm{~s}^{-1}$ ) and moisture flux convergence (shaded, $\mathrm{mm} /$ day) anomalies composited as the difference between the highest and lowest ten salinity years shown in Fig. 2c. The YRV region is marked as a green box
They contribute about $80 \%$ ( $0.8 \mathrm{~mm} /$ day) of the increased moisture flux convergence (about $1 \mathrm{~mm} / \mathrm{day}$ ) in the region. This also means that the thermodynamic contribution in the lower Yangtze River (Fig. 7b) originates from changes in the gradient of specific humidity (Fig. 8d).

Based on Fig. 8, we analyzed lower-tropospheric wind and moisture content anomalies to illustrate the processes responsible for the enhanced dynamic and thermodynamic contributions. The lower-tropospheric wind and humidity is defined as the averages between 1000 and $850 \mathrm{hPa}$. The enhanced dynamic contribution is linked to an intensification of the meridional wind (Fig. 9a). Compared with lowSSS years, the meridional wind increases are in the range $0.25-0.5 \mathrm{~m} / \mathrm{s}$, (about $20 \%$ stronger than the climatological wind over the region). The enhanced meridional wind transports more moisture from the central SCS into the YRV during high SSS years and dynamically increases the MFC. Meanwhile, the enhanced thermodynamic contribution is linked to an intensification of local moisture content anomaly. The humidity in the lower troposphere increases in the eastern YRV region, and maximizes at $115^{\circ} \mathrm{E}, 30^{\circ} \mathrm{N}$ (Fig. 9b), indicating the intensification of the local moisture content. That is to say, during high SSS years, summer precipitation over YRV is associated dynamically with the enhanced northward wind and thermodynamically with increased local humidity content.

\section{Mechanisms linking spring SCS SSS to summer YRV precipitation}

\subsection{SCS SSS signal in the moisture transport}

In the above section, we found that increased moisture convergence and excessive precipitation in the YRV region are mainly associated with enhanced meridional moisture transport from the SCS and locally intensified moisture content in the lower Yangtze River. To examine the SSS signal in this process, the composited SSS, net freshwater flux and moisture flux are shown in Fig. 10. The higher SSS appears in the central SCS. The SSS variation in the central SCS is more responsive to freshwater flux and thus is a better gauge of summer precipitation over land. Different from the central SCS, the salinity in the northern SCS is strongly affected by the salty Kuroshio water intrusion (Zeng et al. 2016b, 2018) and the salinity in the southern SCS is strongly affected by the Mekong river discharge (Zeng et al. 2009; Zeng and Wang 2017). 
(a) Dynamic mass convergengce

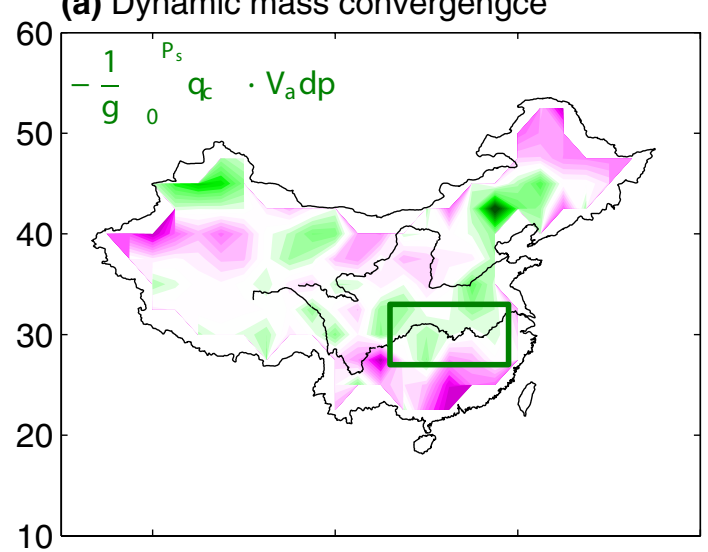

(c) Dynamic moisture gradient

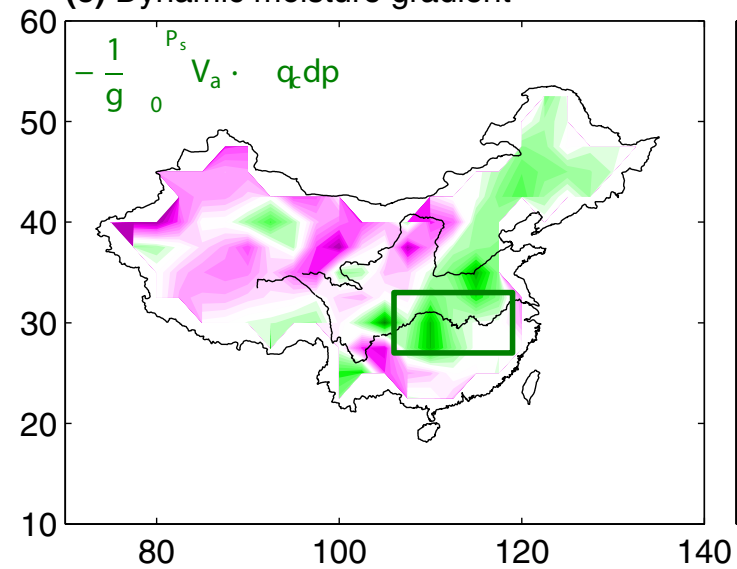

Fig. 8 Dynamic and thermodynamic contributions to summer moisture flux convergence (shaded, $\mathrm{mm} /$ day) anomalies composited as the difference between the highest and lowest ten salinity years shown in Fig. 2c: a dynamic mass convergence term, b thermodynamic mass (b) Thermodynamic mass convergengce

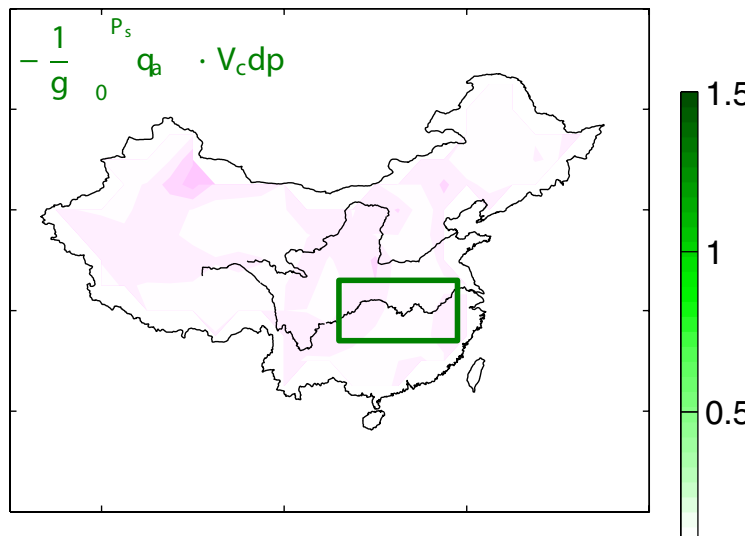

(d) Thermodynamic moisture gradient

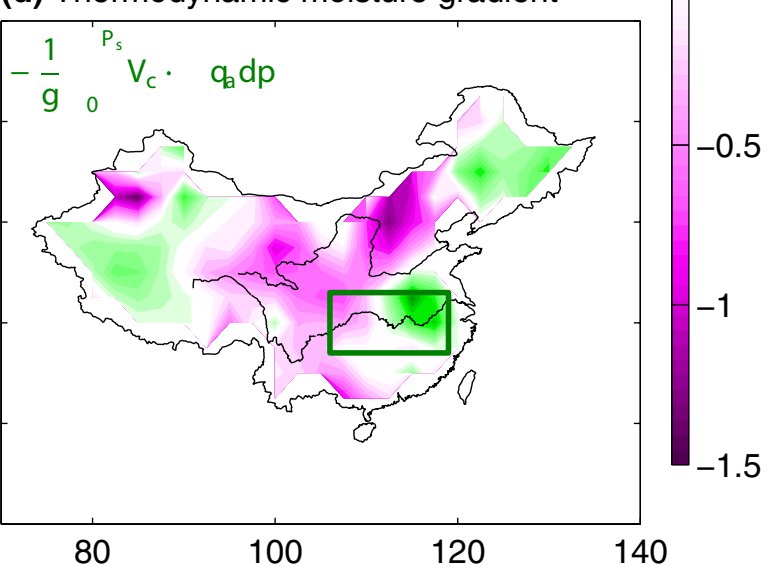

convergence term, $\mathbf{c}$ dynamic moisture gradient term, $\mathbf{d}$ thermodynamic moisture gradient term. The YRV region is marked as a green box
Fig. 9 a Summer composited lower-tropospheric wind anomalies (vectors; $\mathrm{m} / \mathrm{s}$ ) together with climatological moisture content (shaded; g/ $\mathrm{kg}$ ). b Summer climatological lower-tropospheric wind (vectors; $\mathrm{m} / \mathrm{s}$ ) and composited moisture content (shaded; $\mathrm{g} / \mathrm{kg}$ ). Composite analysis is based on the difference between the highest and lowest ten salinity years shown in Fig. 2c (a) Wind anomaly \& climatology moisture

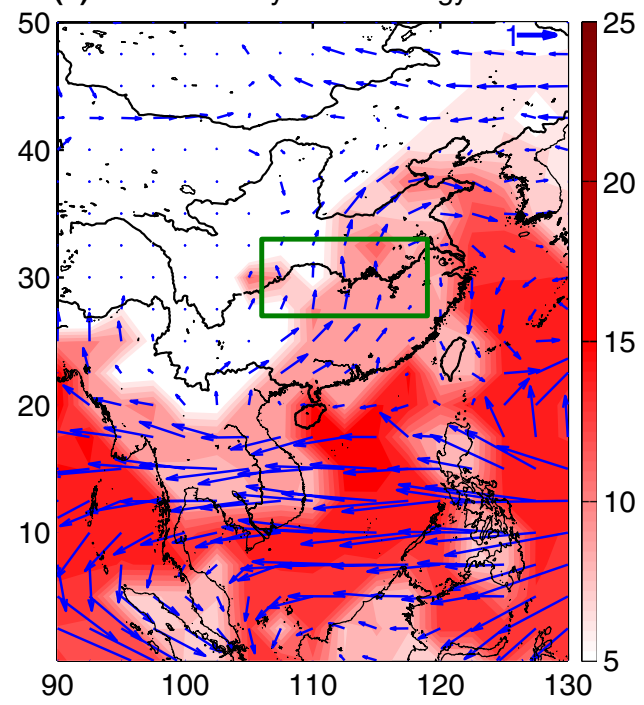

(b) Climatology wind \& moisture anomaly

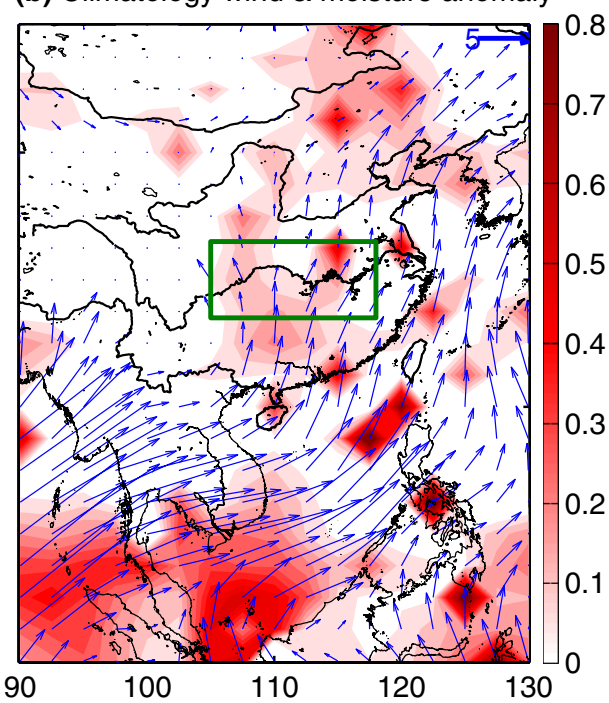


Fig. 10 a Spring and $\mathbf{b}$ summer net freshwater flux (contours; $\mathrm{mm}$ /day, the solid thick contour is the zero freshwater isoline), SSS (shaded; psu) and moisture flux (blue vectors; $\mathrm{kg} \mathrm{m}^{-1} \mathrm{~s}^{-1}$ ) anomalies composited as the difference between the highest and lowest ten salinity years shown in Fig. 2c. Dotted areas indicate that composite freshwater anomalies are significant at the $95 \%$ confidence level (a) Spring SSS \& E-P \& Moisture flux

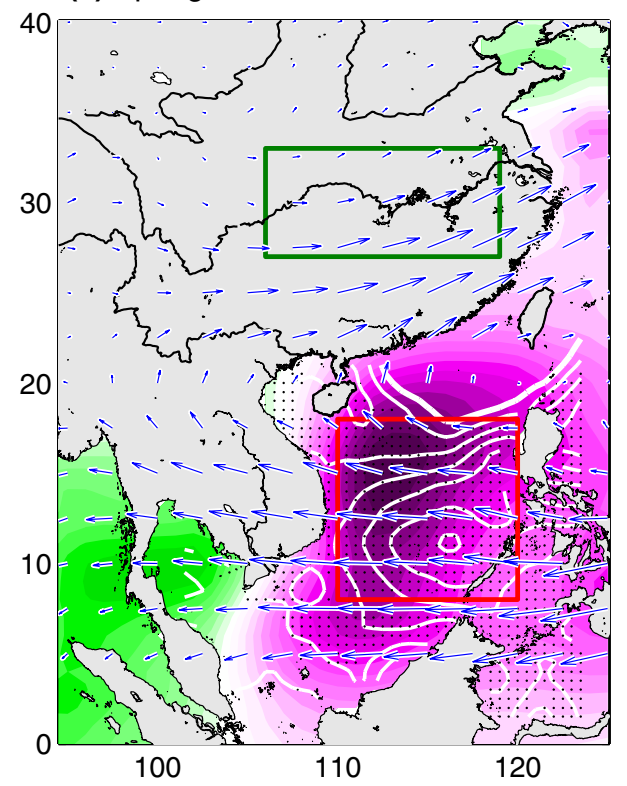

(b) Summer SSS \&E-P \& Moisture flux

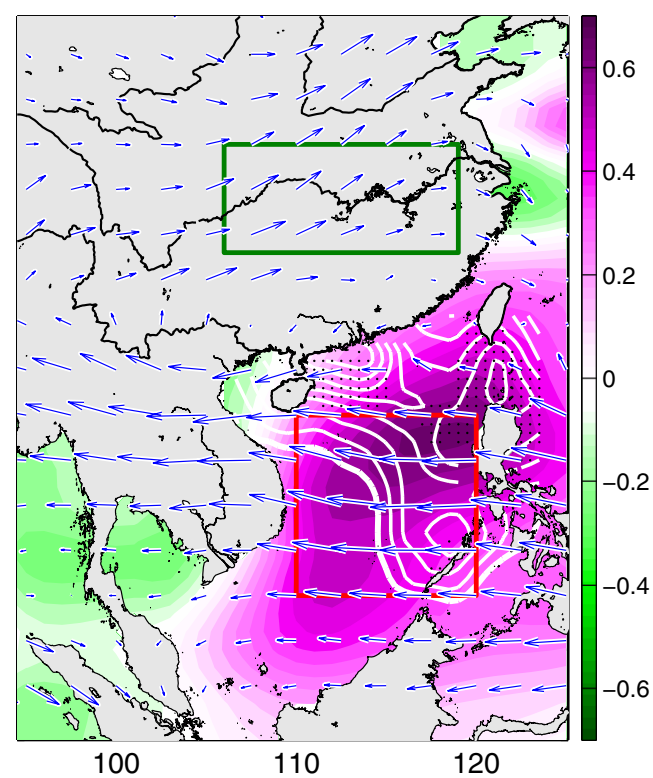

In spring, higher SSS anomalies in the central SCS coincide well with the area of the ocean surface delimited by the net freshwater loss region; i.e., where evaporation is greater than precipitation (Fig. 10a). Note that the position of maximum salinity is slightly shifted from centers of moisture flux divergence and net freshwater flux, reflecting the influence of salinity advection by ocean currents (Zeng et al. 2014; Zeng and Wang 2017). The higher SSS is accompanied by strong moisture flux away from the central SCS to the southern and eastern China. This spring ocean-to-land moisture transport feeds the precipitation over the southern and eastern China shown in Fig. 4a.

From spring to summer, the higher SSS anomaly core and net freshwater loss region move northward slightly (Fig. 4b). The moisture flux shows that the northward shift of the moisture flux source leads to the northward migration of the moisture transport. The area of convergence moves northward from southern China to the YRV region, consistent with the migration of summer precipitation. This leads to the dipole pattern with more precipitation in the YRV but less precipitation in southern China from spring to summer shown in Fig. 4b.

\subsection{Delay mechanism of soil moisture associated with ocean-to-land moisture transport}

After the spring ocean-to-land moisture transport, how does the signal transmit to the subsequent summer? The land surface moisture balance suggests that local MFC or net precipitation minus evaporation is balanced by the local rate of change of soil moisture and residual processes. Li et al. $(2016 a, b)$ identified soil moisture as an important delay mechanism between spring SSS anomalies in the North Atlantic and summer rainfall in the Sahel of Africa and the US Midwest.

The active effect of local soil moisture in regional climate variability is due to its persistence (Delworth and Manabe 1989; Entin et al. 2000; Lo and Famiglietti 2010; McColl et al. 2017). Previous studies suggested that soil moisture content anomalies can persist for 2 or 3 months (Yeh et al. 1984; Entin et al. 2000). McColl et al. (2017) found that the subsequent atmospheric anomalies can be triggered or modulated by the persistent soil moisture anomalies that last for several months.

The domain-averaged moisture flux convergence and the rate of change of soil moisture in southern China and the YRV region show a close relationship (Fig. 11). That is, the increased precipitation over land associated with enhanced moisture flux convergence can be linked to soil moisture changes. In southern China and the YRV region, the soil moisture content benefits from the oceanic moisture supply increase in spring and further increases in summer (Fig. 12a). In particular, the soil moisture memory of southern China and the YRV region in May reaches 3 months (Fig. 12b), similar to the 2.4 months calculated by Liu et al. (2017), which is long enough to affect the subsequent summer climate.

The soil moisture anomaly associated with SSS variations in the central SCS is shown (Fig. 13). The composited spring soil moisture content associated with high SSS is positive in southern China and negative on the Tibetan Plateau and north of the YRV region. The wettest signal is in southeastern China, reflecting the abundant precipitation there. The greater soil moisture anomaly enhances the 


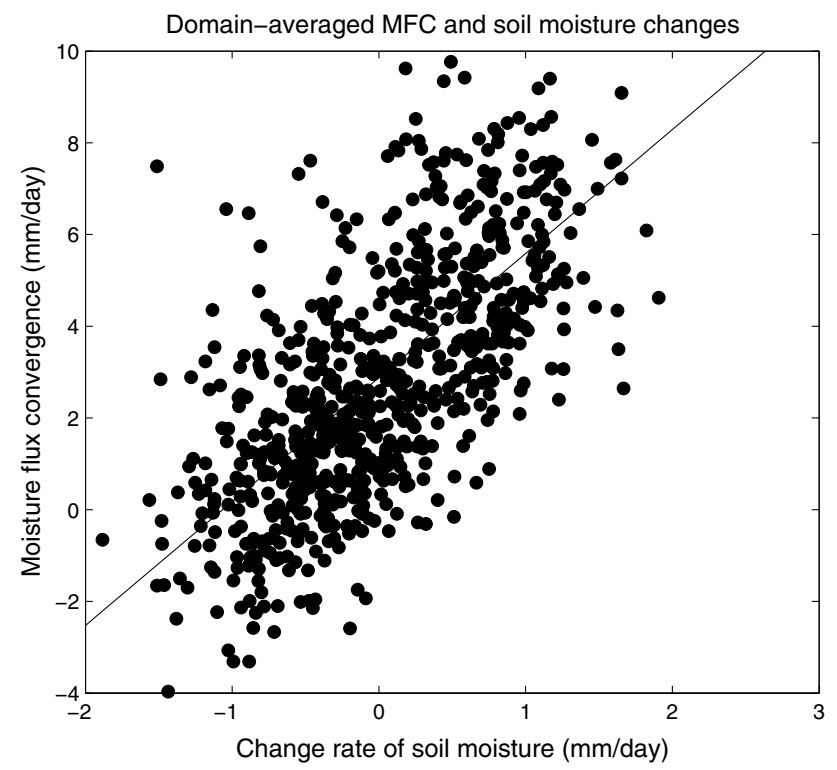

Fig. 11 Relationship between domain-averaged rate of change of soil moisture and moisture flux convergence over southern China and the YRV region. The black line is the least squares linear best-fit line to the sample set west-east gradient of spring soil moisture. The west-east soil moisture gradient persists into summer, although the gradient intensity is weaker in summer. The wet signal over the YRV region strengthens from spring to summer. Previous studies suggested that the wetter soil moisture will raise land-surface evaporation, increase latent and decrease sensible heating, moisten the atmospheric layer and destabilize the troposphere, thereby altering the atmospheric thermal and pressure conditions and circulation (Fast and McCorcle 1990; Zhang and Zuo 2011; Meng et al. 2013; Liu et al. 2017).

To show the possible influence of the soil moisture in southern China on the atmospheric circulation, the zonal soil moisture gradient index is defined as the difference between values in western and eastern parts of southern China (red and blue boxes shown in Fig. 14a). Also shown are the composite of spring and summer sensible heat flux anomalies (Fig. 14a, b), and vertical sections of the meridional wind speed anomalies (Fig. 14c, d). It can be seen that the spring sensible heat flux is larger in the dry southwestern and smaller in the wet southeastern China (Fig. 14a, b). This sensible heat flux pattern persists from spring to summer, although the sensible heat flux anomalies are weaker
Fig. 12 a Climatology monthly mean moisture content ( $\mathrm{mm}$ ) averaged over the southern China and YRV region. b Soil moisture memory (month) in May estimated by 1-month-lag autocorrelation correlation coefficient of soil moisture in May with that in June (a) Monthly soil moisture

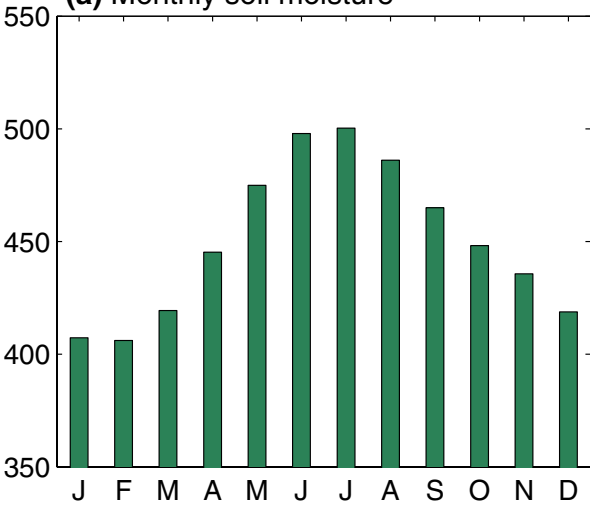

(b) Soil moisture memory in May

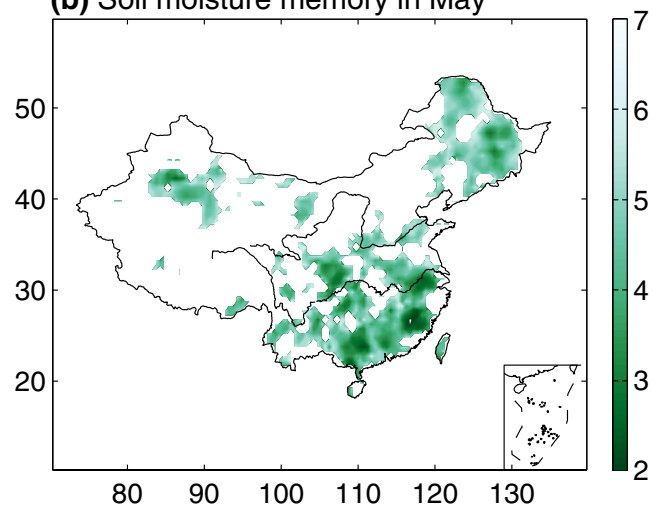

Fig. 13 Soil moisture anomaly composited as the difference between the highest and lowest ten salinity years shown in

Fig. 2c: a spring and $\mathbf{b}$ summer. Dotted areas indicate that the composite soil moisture anomalies are significant at the $95 \%$ confidence level. Soil moisture content in southwestern (red box) and southeastern China (blue box) is used to calculate the west-east soil moisture gradient

\section{(a) Spring soil moisture content}

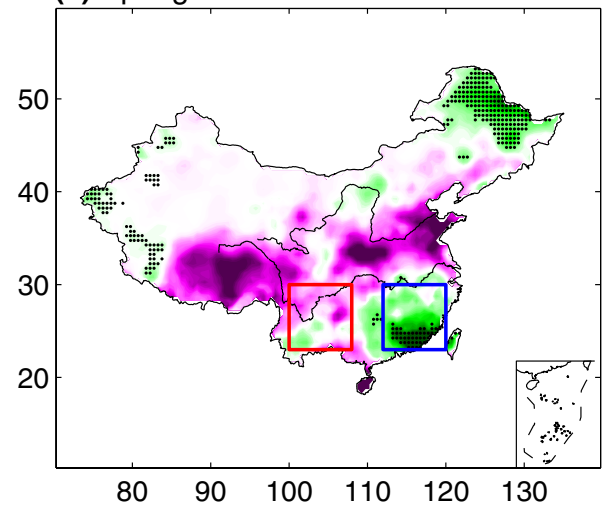

(b) Summer soil moisture content

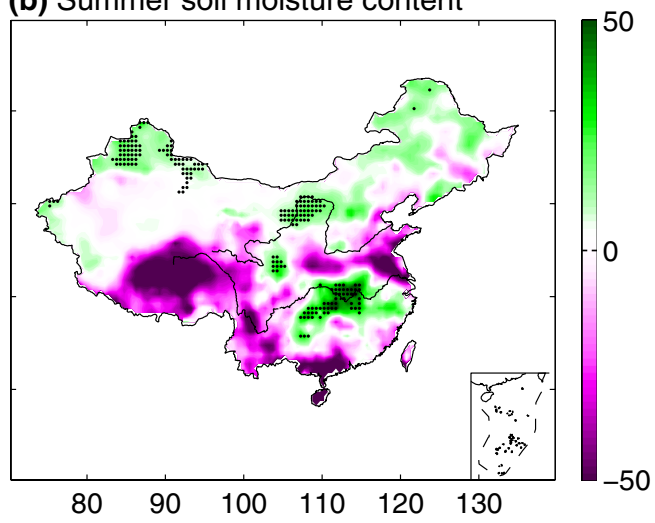


Fig. 14 Composited (a) spring and (b) summer sensible heat flux anomalies (shaded; W/ $\mathrm{m}^{2}$ ), c spring and $\mathbf{d}$ summer vertical sections of meridional wind speed anomalies zonally averaged from $23^{\circ} \mathrm{N}$ to $30^{\circ} \mathrm{N}$ (contour; $\mathrm{m} / \mathrm{s}$ ) which are composited as the difference between the highest and lowest ten soil moisture gradient years based on the soil moisture gradient index calculated from the two areas marked by the red and blue boxes in Fig. 13a

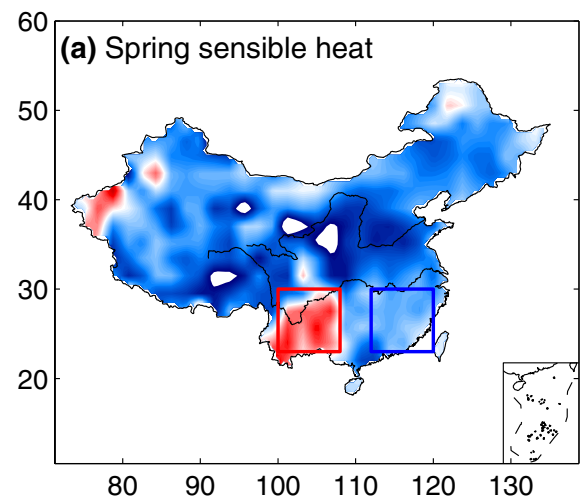

(c) Spring meridional wind speed

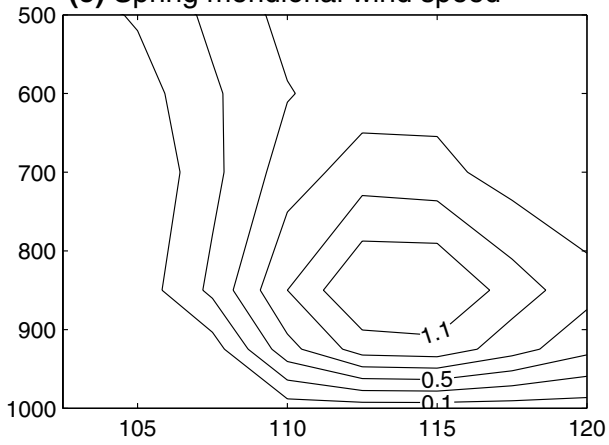

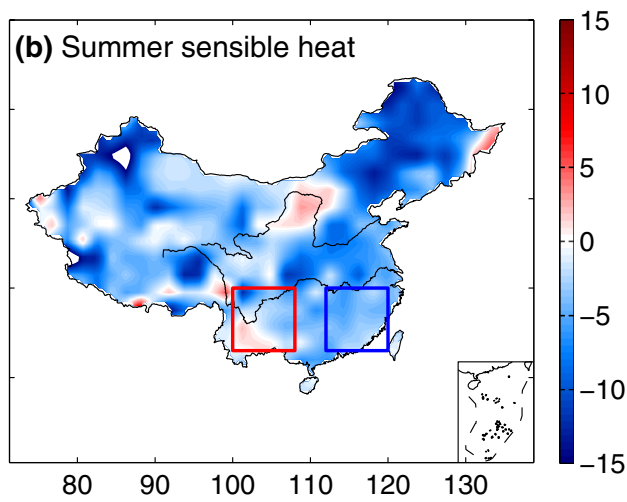

(d) Summer meridional wind speed

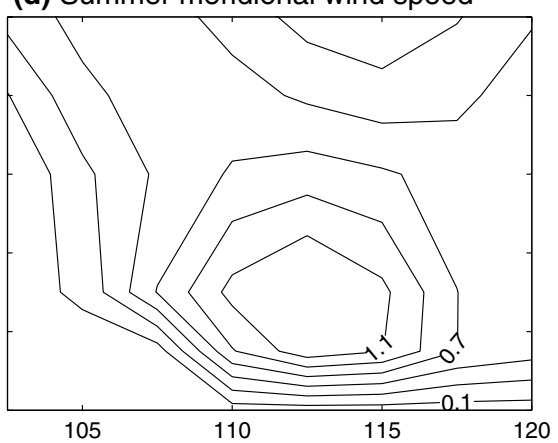

in summer. As shown in Fig. $14 \mathrm{c}$, d, there is a meridional wind anomaly in the lower-tropospheric layers lasting till summer, with the maximum anomaly about $1.1 \mathrm{~m} / \mathrm{s}$ within $900-800 \mathrm{hPa}$. Then the lower-tropospheric wind anomaly is calculated for the differences between the composited years with the highest $10 \%$ and lowest $10 \%$ values of the zonal moisture gradient (Fig. 15). The composite meridional wind strengthens with an enhanced west-east soil moisture gradient. Specifically, the northward meridional wind increases are in the range $0.25-0.5 \mathrm{~m} / \mathrm{s}$ in years with stronger zonal soil moisture gradient years, a similar magnitude to the increase obtained when the wind is composited according to the spring SSS index. This suggests that the soil moisture gradient can largely explain the enhanced dynamic contribution to summer moisture convergence and precipitation. That is to say, the spring ocean-to-land moisture transport from the central SCS and the delay by soil-atmospheric feedback over southern China, triggers a northward wind that dynamically contributes more summer precipitation to the YRV region.

In addition to this dynamic contribution, the spring ocean-to-land moisture transport also increases the local moisture content, feeding the local precipitation over the YRV and moistening the soil. Liu et al. (2017) suggested that the spring precipitation will cause the persistence of a soil moisture anomaly over the lower YRV and eastern China from spring to summer. The persistent wet soil will cause decreased sensible heat flux anomaly, which affects the subsequent summer atmospheric circulation by

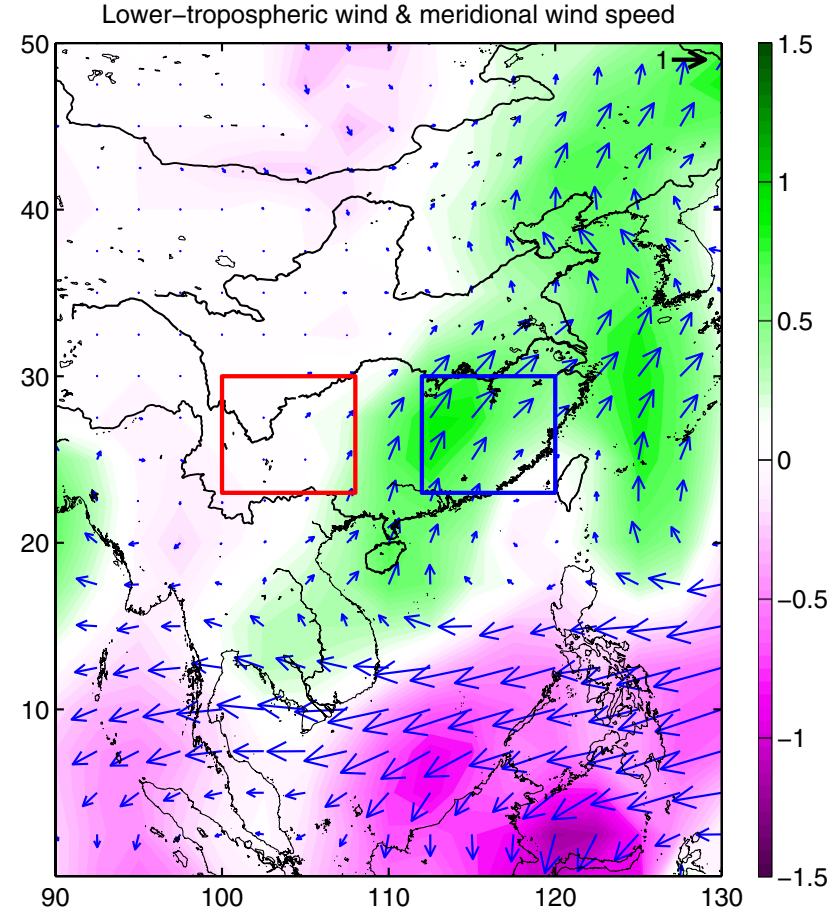

Fig. 15 Summer lower-tropospheric wind anomalies (vectors; $\mathrm{m} / \mathrm{s}$ ) and meridional wind speed (shaded; $\mathrm{m} / \mathrm{s}$ ) composited as the difference between the highest and lowest ten soil moisture gradient years based on the soil moisture gradient index calculated from the two areas marked by the red and blue boxes in Fig. 13a 
suppressing sea breezes. They also confirmed the importance of soil moisture memory in the persistence of the heat flux anomaly, atmospheric circulation and precipitation from spring to summer in the YRV region by removing the role of the soil moisture anomaly from the regression.

The combined dynamic and thermodynamic effects described above suggest the following sequence. First, a positive spring SSS anomaly in the central SCS indicates enhanced moisture transport to southeastern China and YRV that strengthens the zonal soil moisture gradient that persists into summer. Second, summer precipitation in the YRV is enhanced by a dynamic contribution from stronger northward meridional winds and a thermodynamic contribution from local higher moisture content and soil moisture feedback. Thus, spring SSS in the central SCS can be utilized as an indicator of subsequent summer precipitation over the YRV region.

\section{Conclusions and discussion}

Water in the ocean is the ultimate source of terrestrial rain. While about $50 \%$ of surface evaporation from the ocean falls back as local precipitation, the rest is exported from the evaporation-dominated subtropical high pressure systems. Anomalously large water export leads to higher SSS, guaranteeing that some part of the climate system will experience more rain. Recent studies have found that seasonal anomalies in SSS in particular areas of the ocean have remarkable skill for predicting terrestrial rain in the next season in certain regions on land (Li et al. 2016a, b, 2018; Liu et al. 2018; Chen et al. 2019). The SCS is an important moisture source of terrestrial rain over China. Anomalously large moisture transport can generate higher SSS in the SCS and excessive precipitation over China. In this study, the possibility of predicting land precipitation using SSS in the SCS is explored from the perspective of the oceanic water cycle.

The correlation matrix of spring SSS and summer precipitation gives a first SVD mode with a variance contribution of $42.6 \%$ that shows a close relationship between SSS in the SCS and precipitation over China. Statistical analysis suggests that the most significant relationship is between spring SSS in the central SCS and summer YRV precipitation. Up to $50 \%$ variance of summer YRV precipitation can be accounted for using spring SSS in the central SCS. This indicates that the spring SSS in the central SCS can be a good indicator for the subsequent summer YRV precipitation. In addition the predictive value provided by spring SSS is independent of the SST-based ENSO index.

The linkage between spring SSS in the central SCS and summer YRV precipitation is established by ocean-to-land moisture transport by atmospheric processes and the delay due to land-atmospheric (soil moisture) feedback (Fig. 16).
In spring, oceanic moisture transported away from the sea surface generates high SSS in the central SCS. The resulting moisture flux converges directly onto southeastern China and YRV, increasing local soil moisture. The west-east (dry in southwestern China and wet in southeastern China) soil moisture gradient persists for about 3 months. The analysis indicates that the subsequent summer meridional winds become stronger as a result of the enhanced west-east soil moisture gradient and dynamically contribute to the summer YRV precipitation. Note that some numerical experiments are needed to provide further evidence of this land-atmosphere interaction. The continuously high soil moisture from spring to summer over the lower Yangtze River also contributes thermodynamically to the summer precipitation by intensifying local tropospheric moisture content.

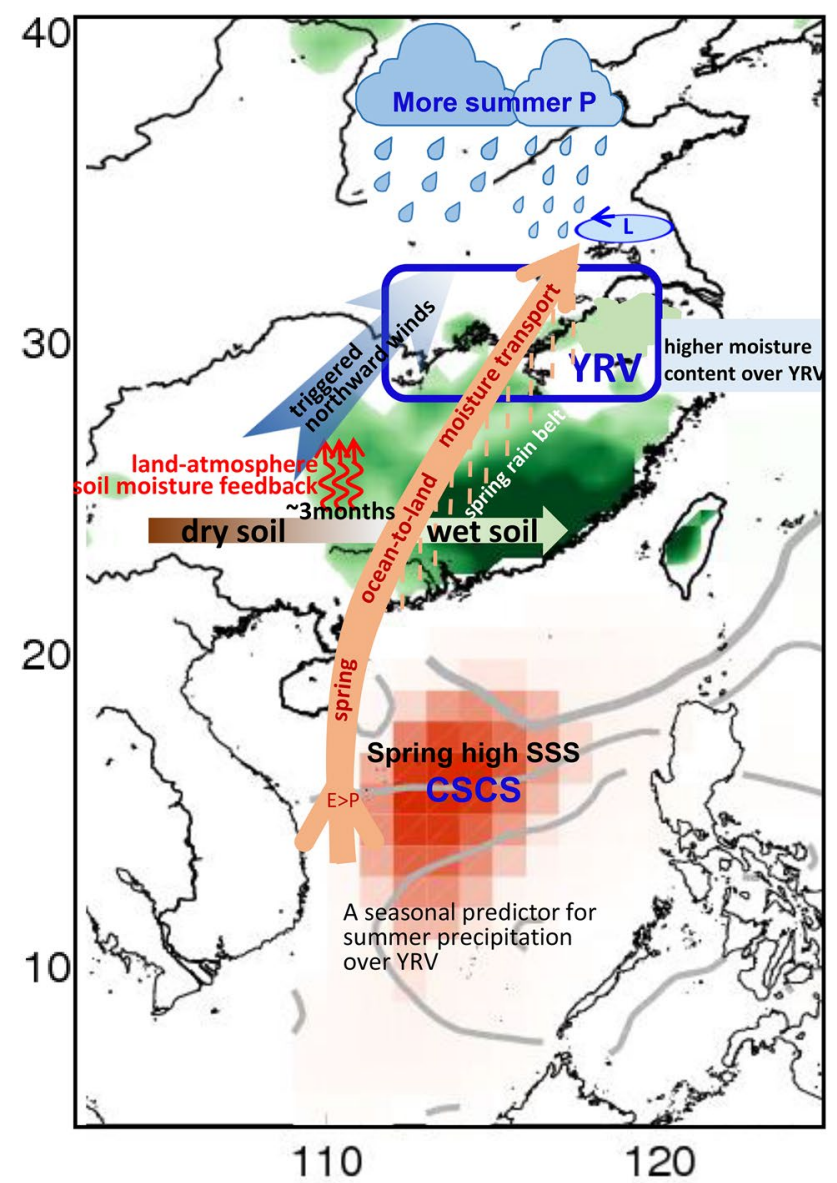

Fig. 16 Schematic illustrating the seasonal predictability of the spring SSS anomaly in the central SCS and precipitation over YRV established through ocean-to-land moisture transport by atmospheric processes and land-atmosphere feedback. In spring, the moisture supply from the ocean surface that generates higher SSS feeds the precipitation over the YRV and southern China. Enhanced moisture transport triggered by northward winds arising from land-atmosphere soil moisture feedback, and the higher moisture content over YRV, generate excessive precipitation in the subsequent summer 
The information provided by the central SCS SSS, especially in the preceding spring, is valuable for the prediction of summer precipitation over the YRV region. In addition, there are many interesting phenomena that we have not considered in detail in this study. For example, the first SVD mode indicates that there is a high correlation between spring SSS in the SCS and summer precipitation over western Guangdong. Thus there may be the potential to use the spring SSS in the SCS to predict the summer precipitation in regions other than the YRV. Also, there is a low salinity core just east of the Yangtze River mouth in the first SVD mode of spring SSS, suggesting that the near-shore spring SSS may be a good indicator of Yangtze River discharge. Further studies are needed to explore these issues.

Acknowledgements This research has been supported by the National Natural Science Foundation of China (Nos. 41776025, 41476014, 41606030, 41806027, 41806035). RWS was supported by NSF Grant ICER-1663704. LL was supported by NSF-ICER-1663138. QW was also sponsored by the Pearl River S\&T Nova Program of Guangzhou (201906010051). LZ was also supported by the Innovation Academy of South China Sea Ecology and Environmental Engineering (ISEE), Chinese Academy of Sciences, and the Southern Marine Science and Engineering Guangdong Laboratory (Guangzhou).

Open Access This article is distributed under the terms of the Creative Commons Attribution 4.0 International License (http://creativeco mmons.org/licenses/by/4.0/), which permits unrestricted use, distribution, and reproduction in any medium, provided you give appropriate credit to the original author(s) and the source, provide a link to the Creative Commons license, and indicate if changes were made.

\section{References}

Bretherton CS, Smith C, Wallace JM (1992) An intercomparison of methods for finding coupled patterns in climate data. J Clim 5:541-560

Brubaker KL, Entekhabi D, Eagleson PS (1993) Estimation of continental precipitation recycling. J Clim 6:1077-1089

Chen T-C, Pfaendtner J (1993) On the atmospheric branch of the hydrological cycle. J Clim 6:161-167

Chen M, Xie P, Janowiak JE, Arkin PA (2002) Global land precipitation: a 50-yr monthly analysis based on gauge observations. J Hydrometeor 3:249-266

Chen B, Qin H, Chen G, Xue H (2019) Ocean salinity as a precursor of summer rainfall over the East Asian monsoon region. J Clim. https://doi.org/10.1175/JCLI-D-18-0756.1

Delworth T, Manabe S (1989) The influence of soil wetness on nearsurface atmospheric variability. J Clim 2:1447-1462

Ding Y, Chan JCL (2005) The East Asian summer monsoon: an overview. Meteorol Atmos Phys 89:117-142

Durack PJ (2015) Ocean salinity and the global water cycle. Oceanography 28:20-31

Durack PJ, Wijffels SE (2010) Fifty-year trends in global ocean salinities and their relationship to broad-scale warming. J Clim 23:4342-4436

Durack PJ, Wijffels SE, Matear RJ (2012) Ocean salinities reveal strong global water cycle intensification during 1950 to 2000. Science 336:455-458
Entin JK, Robock A, Vinnikov KY, Hollinger SE, Liu S, Namkhai A (2000) Temporal and spatial scales of observed soil moisture variations in the extratropics. J Geophys Res 105:11865-11877

Fan Y, van den Dool H (2004) Climate Prediction Center global monthly soil moisture data set at 0.5 -degree resolution for 1948 to present. J Geophys Res 109:D10102. https://doi. org/10.1029/2003JD004345

Fast JD, McCorcle MD (1990) A two-dimensional numerical sensitivity study of the Great Plains low-level jet. Mon Wea Rev 118:151-163

Gimeno L, Drumond A, Nieto R, Trigo RM, Stohl A (2010) On the origin of continental precipitation. Geophys Res Lett 37:L13804. https://doi.org/10.1029/2010GL043712

Good SA, Martin MJ, Rayner NA (2013) EN4: quality controlled ocean temperature and salinity profiles and monthly objective analyses with uncertainty estimates. J Geophys Res Oceans 118:6704-6716

He J, Zhu Z (2015) The relation of South China Sea monsoon onset with the subsequent rainfall over the subtropical East Asia. Int J Climatol 35(15):4547-4556

Jones RH (1975) Estimating the variance of time averages. J Appl Meteorol 14:159-163

Kalnay E, Kanamitsu M, Kistler R, Collins W, Deaven D, Gandin L, Iredell M, Saha S, White G, Woollen J, Zhu Y, Leetmaa A, Reynolds R, Joseph JD (1996) The NCEP/NCAR 40-year reanalysis project. Bull Am Meteorol Soc 77(3):437-472

Lagerloef G, Boutin J, Chao Y, Delcroix T, Font J, Niiler P, Reul N, Riser SJ, Schmitt R, Stammer D, Wentz F (2010) Resolving the global surface salinity field and variations by blending satellite and in situ observations. In: OceanObs 09. European Space Agency, pp 587-597

Lei Y, Hoskins B, Slingo J (2011) Exploring the interplay between natural decadal variability and anthropogenic climate change in summer rainfall over china Part I: observational evidence. J Clim 24(17):4584-4599

Li L, Li W, Barros AP (2013) Atmospheric moisture budget and its regulation of the summer precipitation variability over the southeastern United States. Clim Dyn 41:613-631

Li L, Schmitt RW, Ummenhofer CC, Karnauskas KB (2016a) North Atlantic salinity as a predictor of Sahel rainfall. Sci Adv 2:e1501588

Li L, Schmitt RW, Ummenhofer CC, Karnauskas KB (2016b) Implications of north atlantic sea surface salinity for summer precipitation over the us midwest: mechanisms and predictive value. J Clim 29(9):3143-3159

Li T, Wang B, Wu B, Zhou T, Chang C-P, Zhang R (2017) Theories on formation of an anomalous anticyclone in Western North Pacific during El Niño: a review. J Meteor Res 31(6):987-1006

Li L, Schmitt RW, Ummenhofer CC (2018) The role of the subtropical north atlantic water cycle in recent us extreme precipitation events. Clim Dyn. 50:1291-1305

Liu L, Zhang R, Zuo Z (2017) Effect of spring precipitation on summer precipitation in eastern china: role of soil moisture. J Clim 30:9183-9194

Liu T, Schmitt RW, Li L (2018) Global search for autumn-lead sea surface salinity predictors of winter precipitation in southwestern United States. Geophys Res Lett 45:8445-8454

Lo M-H, Famiglietti JS (2010) Effect of water table dynamics on land surface hydrologic memory. J Geophys Res 115:D22118. https:// doi.org/10.1029/2010JD014191

Lynch P (1988) Deducing the wind from vorticity and divergence. Mon Weather Rev 116:86-93

Mccoll KA, Alemohammad SH, Akbar R, Konings AG, Yueh S, Entekhabi D (2017) The global distribution and dynamics of surface soil moisture. Nat Geosci 10(2):100-104 
Meng L, Long D, Quiring SM, Shen Y (2013) Statistical analysis of the relationship between spring soil moisture and summer precipitation in east china. Int J Climatol 34(5):1511-1523

Prohaska JT (1976) A technique for analyzing the linear relationships between two meteorological fields. Mon Weather Rev 104:1345-1353

Schanze JJ, Schmitt RW, Yu LL (2010) The global oceanic freshwater cycle: a state-of-the-art quantification. J Mar Res 68:569-595

Schmitt RW (1995) The ocean component of the global water cycle. Rev Geophys 33(Suppl.):1395-1409

Schmitt RW (2008) Salinity and the global water cycle. Oceanography 21:12-19

Seager R, Henderson N (2013) Diagnostic computation of moisture budgets in the ERA-Interim reanalysis with reference to analysis of CMIP-archived atmospheric model data. J Clim 26:7876-7901

Skliris N, Marsh R, Josey SA, Good SA, Liu C, Allan RP (2014) Salinity changes in the world ocean since 1950 in relation to changing surface freshwater fluxes. Clim Dyn 43(3-4):709-736

Tao S, Chen L (1987) A review of recent research on the East Asian summer monsoon in China. In: Chang C-P, Krishnamurti TN (eds) Monsoon meteorology. Oxford University Press, Oxford, pp 60-92

Terray L, Corre L, Cravatte S, Delcroix T, Reverdin G, Ribes A (2012) Near-surface salinity as nature's rain gauge to detect human influence on the tropical water cycle. J Clim 25:958-977

Trenberth KE, Guillemot CJ (1995) Evaluation of the global atmospheric moisture budget as seen from analyses. J Clim 8:2255-2272

Trenberth KE, Fasullo JT, Mackaro J (2011) Atmospheric moisture transports from ocean to land and global energy flows in reanalyses. J Clim 24:4907-4924

Wallace JM, Smith C, Bretherton CS (1992) Singular value decomposition of wintertime sea surface temperature and $500-\mathrm{mb}$ height anomalies. J Clim 5:561-576

Wang B, Ho L, Zhang Y, Lu M-M (2004) Definition of South China Sea monsoon onset and commencement of the East Asia summer monsoon. J Clim 17:699-710

Wu R, Hu ZZ, Kirtman BP (2003) Evolution of ENSO-related rainfall anomalies in East Asia. J Clim 16(22):3742-3758

Yang K, Zhang J (2016) Spatiotemporal characteristics of soil temperature memory in china from observation. Theor Appl Climatol 126(3-4):1-11

Yeh TC, Weterald RT, Manabe S (1984) The effect of soil moisture on the short-term climate and hydrology change-a numerical experiment. Mon Weather Rev 112:474-490
Yu L (2011) A global relationship between the ocean water cycle and near-surface salinity. J Geophys Res 116:C10025. https://doi. org/10.1029/2010JC006937

Zeng L, Wang D (2017) Seasonal variations in the barrier layer in the South China Sea: characteristics, mechanisms and impact of warming. Clim Dyn 48:1911-1930

Zeng L, Du Y, Xie S-P, Wang D (2009) Barrier layer in the South China Sea during summer 2000. Dyn Atmos Oceans 47:38-54

Zeng L, Liu WT, Xue H, Xiu P, Wang D (2014) Freshening in the South China Sea during 2012 revealed by Aquarius and in situ data. J Geophys Res Oceans 119:8296-8314

Zeng L, Wang D, Chen J, Wang W, Chen R (2016a) SCSPOD14, a South China Sea physical oceanographic dataset derived from in situ measurements during 1919-2014. Sci Data 3:160029. https ://doi.org/10.1038/sdata.2016.29

Zeng L, Wang D, Xiu P, Shu Y, Wang Q, Chen J (2016b) Decadal variation and trends in subsurface salinity from 1960 to 2012 in the northern South China Sea. Geophys Res Lett 43:12181-12189

Zeng L, Chassignet E, Schmitt RW, Xu X, Wang D (2018) Salinification in the South China Sea since late 2012: a reversal of the freshening since 1990s. Geophys Res Lett 45(6):2744-2751

Zhang R (2015) Changes in East Asian summer monsoon and summer rainfall over eastern China during recent decades. Sci Bull 60:1222-1224

Zhang Y-L, You W-J (2014) Social vulnerability to floods: a case study of Huaihe River Basin. Nat Hazards 71:2113-2125

Zhang R, Zuo Z (2011) Impact of spring soil moisture on surface energy balance and summer monsoon circulation over East Asia and precipitation in east China. J Clim 24:3309-3322

Zhou T, Yu R (2005) Atmospheric water vapor transport associated with typical anomalous summer rainfall patterns in China. J Geophys Res 110:D08104. https://doi.org/10.1029/2004JD005413

Zhou T, Wu B, Wang B (2009) How well do atmospheric general circulation models capture the leading modes of the interannual variability of the Asian-Australian monsoon? J Clim 22:1159-1173

Zhu Z, Li T (2017) Empirical prediction of the onset dates of South China Sea summer monsoon. Clim Dyn 48(5):1633-1645

Publisher's Note Springer Nature remains neutral with regard to jurisdictional claims in published maps and institutional affiliations. 